\title{
A patient-based national survey on postoperative pain management in France reveals significant achievements and persistent challenges
}

Dominique Fletcher ${ }^{1,3}$, Christophe Fermanian², Alain Mardaye ${ }^{2}$, Philippe Aegerter $^{2}$, Pain and regional anesthesia committee of the French Anesthesia and Intensive Care Society (SFAR)

1 Université de Versailles St-Quentin, AP-HP, Hôpital Raymond Poincaré, Service d'Anesthésie Réanimation Chirurgicale, 104 boulevard Raymond Poincaré 92380 Garches, France

${ }^{2}$ Université de Versailles St-Quentin, AP-HP, Hôpital Ambroise Paré, Clinical Research Unit, 9 avenue Charles de Gaulle, 92100 Boulogne, France

${ }^{3}$ INSERM, U-792, Hôpital Ambroise Paré, Centre d'Evaluation et de Traitement de la Douleur, F-92100 France; Université Versailles Saint-Quentin, Versailles, F-78035 France

Corresponding author : Dominique Fletcher

Université de Versailles St-Quentin, AP-HP, Hôpital Raymond Poincaré, Service d'Anesthésie Réanimation Chirurgicale, 104 boulevard Raymond Poincaré 92380 Garches, France. tel 0147107622, fax 0147107623 ; Email : dominique.fletcher@rpc.ap-hop-paris.fr

Manuscript: forty one pages, 9 tables and 1 appendix 


\section{Abstract (249 words)}

We carried out a national survey on postoperative pain (POP) management in a representative sample (public/private, teaching/non teaching, size) of 76 surgical centers in France. Based on medical records and questionnaires, we evaluated adult patients 24 hours after surgery, concerning information, pre and postoperative pain, evaluation, treatment and side effects. A local consultant provided information about POP management. Data were recorded for 1900 adult patients, $69.3 \%$ of whom remembered information on POP. Information was mainly delivered orally $(90.3 \%)$ and rarely noted on the patient's chart (18.2\%). Written evaluations of POP were frequent on the ward (93.7\%) with appropriate intervals (4.1 (4.0) hours), but not frequently prescribed (32.7\%). Pain evaluations were based on visual analog scale (21.1\%), numerical scale $(41.2 \%)$, verbal scale $(13.8 \%)$ or non numerical tool (24\%). Pain was rarely a criterion for recovery room discharge $(19.8 \%)$. Reported POP was mild at rest (2.7 (1.3), moderate during movement (4.9 (1.9) and intense at its maximal level (6.4 (2.0). Incidence of side effects was similar according to patient (26.4\%) or medical chart (25.1\%) including mostly nausea and vomiting (83.3\%). Analgesia was frequently initiated during anesthesia (63.6\%). Patient-controlled analgesia (21.4\%) was used less frequently than subcutaneous morphine (35.1\%) whose prescription frequently did not follow guidelines. Non-opioid analgesics used included paracetamol (90.3\%), ketoprofen (48.5\%) and nefopam (21.4\%). Epidural (1.5\%) and peripheral (4.7\%) nerve blocks were underused. Evaluation (63.4\%) or treatment $(74.1 \%)$ protocols were not available for all patients.

This national, prospective, patient-based, survey reveals both progress and persistent challenges in POP management.

\section{Key words}

Postoperative pain, national survey, improvement 


\section{Introduction (491 words)}

Surveys evaluating pain in hospitals have been conducted since the early sixties and continue to be published regularly [41]. Postoperative pain (POP) control has frequently been shown to be inadequate in many countries including France, in general surveys $[1,13,26,28]$ or studies focusing on patients undergoing surgery in individual teaching hospitals $[48,62]$ at national $[6,15,36,37,44,45,53]$ or international level $[8,54]$. The most frequent detected failings concern the information of the patient, limited pain evaluation, the under use of opioid and regional anesthesia techniques and inadequate organization. However, POP is a major concern for hospitalized patients [13] and may interfere with postoperative recover and increase postoperative morbidity [14]. Ad hoc evidenced-based guidelines for improving pain management, have been issued in several countries $[4,43,50,51,63]$. Acute pain services have been created either based on anesthesiologist staffs $[42,56]$ or dedicated pain nurses [55]. Interventions designed to improve quality have been described in single hospital $[7,30,32]$ or group of hospitals [33]. Medical students are now trained in pain evaluation and management and many medical meetings provide information about postoperative pain control.

The French Ministry of Health has supported effort to improve pain management, by initiating successive plans since 1994 concerning the right to pain relief for patients [20], nurses' professional obligations to evaluate pain [19], pain control recommendations for health establishments [18] and the obligation to provide patients with information [40]. Acute pain management has also recently been identified as an important element of evaluations of the professional activity of anesthesiologists [57] and of health establishments seeking certification [52].

A survey of anesthesia practice in France in 1996 has highlighted a $120 \%$ increase in number of anesthetics procedures since 1980, with a 14 fold increase in the number of regional anesthetic procedures [17]. Between 1990 and 1996, significant advances in knowledge and attitudes regarding pain and its management in the French general 
population occurred, with greater awareness of the importance of acute pain treatment and acceptance of morphine use [39].

No large-scale patient-based survey has evaluated changes in POP control in France since 1996 [48]. National surveys have been performed in other countries based principally on questionnaires sent to institution or professionals $[6,15,34,36,44,45]$. Strategies for improving responses to postal questionnaires have been proposed [29], but the information provided by such declarative studies is not reliable because they globally overestimate the quality of care [11]. We therefore designed an observational national survey of POP control for inpatient surgery. The aim was to obtain data for adult inpatients, 24 hours after surgery, from a representative sample of surgical centers. We used three sources of information: the patient, the patients' chart and interviews with healthcare providers. The French Anesthesia and Intensive Care Society (SFAR) and the Ministry of Health supported this survey, which was designed to evaluate the impact of the previous ministerial pain plan and French Anesthesia and Intensive Care Society POP management guidelines in routine daily practice, with a view to revising these guidelines and assisting policy-makers with decisions concerning future recommendations for POP control [46].

\section{Methods}

\section{Sample}

We used French Ministry of Health statistics on surgical activity to build a representative sample of surgical centers according to teaching status, source of funding (public/private) and level of surgical activity. Based on these criteria, we defined five strata: teaching hospitals ( $n=49)$, large ( 2700 surgical cases per year) public hospitals $(n=1091)$, small public hospitals $(n=106)$, large ( $>3200$ surgical cases per year) private centers $(n=269)$ and small private centers $(n=268)$. Centers performing fewer than five surgical procedures per day were excluded. Sample size was calculated to detect severe pain at rest in $50 \%$ of 
patients, based on incidence previously reported in similar survey [48], with a $2.5 \%$ precision and a $5 \% \alpha$ error. As a compromise between precision, number of visits and local acceptability, we decided to investigate 25 patients at each centre. As postoperative pain is managed by a single anesthesia department at each center, precision may be decreased by clustering, but increased by stratification. Taking into account a global clustering effect of $\rho=0.15$ (i.e. a design effect of 4.6 ), we set the sample size at 2000 patients. The order of magnitude of this effect was confirmed after interim analysis 6 months into the survey. We performed a self-weighted two-stage sampling design: (i) the number of selected hospitals in each stratum was proportional to the number of surgical cases in the corresponding stratum, and (ii) each hospital in a particular stratum was chosen with unequal probability, proportional to the number of annual surgical cases in this hospital.

\section{Questionnaires}

Experts in postoperative pain control (DF, members of the French Anesthesia and Intensive Care Society Pain and Regional Anesthesia Committee) designed three questionnaires to collect data from the patient (21 items), the patient's chart (80 items) and an interview with the local postoperative pain specialist (50 items). These questionnaires were used to crosscheck data concerning the information of the patient, pre- and postoperative pain, pain evaluation, treatment, side effects and pain management at the center (Appendix). They were tested and modified in a pilot survey including one centre from each stratum.

Preoperative pain evaluation was introduced during the survey and data were available for 750 patients. Pain at rest and pain during movement were evaluated at the time of the auditor's visit, using a numerical scale (NS) (0: no pain; 10 unbearable pain), with severe pain described as an NS pain intensity score $\geq 7$, as previously suggested [5]. The maximal pain intensity reported by the patient was defined as the most intense pain between surgery and auditor's visit. Maximal pain scores at rest and during movement in the recovery room (RR) during the first night after surgery and the day after surgery, before the auditor's visit, were collected on the patient's chart. Side effects incidence was evaluated through both patient's interview and patient's chart analysis. They were considered as present when at 
least one episode since surgery was either described by the patient or recorded in the patient's chart. All information concerning analgesics prescription and administration was obtained from the patient's chart. As previously described [24], we analyzed the extent to which opioid or non opioid analgesic drug prescriptions were respected, by comparing the prescriptions made by physicians with drug administrations by nurses.

According to previous recommendations on minimum requirements for pain management [2], we chose a minimum of one written evaluation of pain as the criterion to evaluate the frequency of written pain evaluation. Pain intensity was evaluated with a visual analog scale (VAS), numerical scale (NS) or verbal pain scale (VPS). All these scales were considered to be numerical evaluation tools. Other tools for pain evaluation (e.g. qualitative appreciations such as "patient comfortable", "no pain" or symbols used for evaluation such as "pain +++") were considered to be non numerical tool of evaluation. Pain was considered as a criterion for RR discharge if a pain score was identified on patient's chart at the time of RR discharge. Nurses were interviewed in the $R R$ and surgical department about the frequency of pain evaluation, pain evaluation as an RR discharge criterion, the timing of pain evaluation (i.e. pain evaluation after treatment) and the evaluation of side effects of analgesics. The patient's satisfaction score concerning staff behavior and global management of pain was evaluated with a numerical scale (NS) (0: not satisfied at all, 10: totally satisfied). Treatment protocols are recommendations for the prescription of analgesic drugs. They may be strictly prewritten orders or guidelines for both nurses and physicians available in surgical wards. Postoperative pain quality programs involve the explicit autoevaluation of postoperative pain management, organized by healthcare professionals.

\section{$\underline{\text { Realization of the survey }}$}

After selection, a letter was sent to both the hospital direction and the head of the anesthesia department of a selected center to obtain simultaneous agreement for participation. In case of no response within 2 months, a second letter was sent to both. In case of no response or 
clear refusal within two months after the second letter, the center was withdrawn from the survey and another one was selected.

A single auditor (AM) was recruited and trained in postoperative pain management and the carrying out of the survey, particularly during a pilot survey. Based on the results of the pilot study, the auditor visited one center per week, and reviewed 25 cases at that center. Informed consent was not considered necessary by the local ethic committee (Comité de Protection des Personnes pour la Recherche Biomédicale, Boulogne, France). All participants had to give their verbal consent. The randomization of patients at each center was based on a random sample drawing program designed by the statistician. The auditor randomly drew 25 patients from among those whose surgery had begun before midnight on the day before the visit. For institutions with multiple operative sites, we devised a procedure to take into account the representativity of each operative site based on the number of patients undergoing surgery at each site. Patients under 18 years of age or undergoing day surgery were excluded. The patient completed the anonymous questionnaire with the help of the auditor; chart questionnaire was filled by consulting anesthesiology preoperative visit, the intraoperative monitoring, the postoperative prescription and patient's monitoring in the RR and surgical department and interviewing nurse for specific questions; the pain referent collected specific information then filled his questionnaire at the end of the survey, with help of the auditor.

\section{Data analysis}

Quantitative data (pre and postoperative pain scores, pain relief scores, satisfaction scores, intensity of side effects, dose and interval for analgesics, interval for pain evaluation) are presented as mean and standard deviation (SD). Global variances were adjusted for the sampling design using the Horvitz-Thompson estimator [35,64]. ANOVA was used for the comparison of continuous data between groups. Percentages are presented with denominator (total number minus missing data) and numerator (number of patient with the studied characteristic) and are rounded to one decimal place. Values of $p<0.05$ were 
considered significant. Analyses were carried out by the clinical research unit (CF, PA) using SAS (Cary, NC).

\section{Results}

\section{$\underline{\text { Sample of patients studied }}$}

One hundred and twenty six surgical centers were contacted. Twenty nine centers did not respond to two successive solicitations. Thirteen centers declined participation. Eight centers were not included since we already had sufficient participants.

One thousand and nine hundred patients were included from June 2004 to July 2006 in 76 centers. Patient's number was 250, 150, 275, 425 and 800 in teaching public hospital, small and large non-teaching public and small and large private institutions respectively. The characteristics of the patients and surgery are given in table 1.

\section{Preoperative information}

Data concerning the information about POP given to patients before surgery are listed in table 2 . We found that $30.7 \%$ of the patients were unable to remember the information they were given. Information was most given orally $(90.3 \%(1190 / 1318)$ and a proof that it was delivered to the patient was noted in $18.2 \%$ (346/1899) of the patients' charts. However, $95.3 \%(1251 / 1313)$ of patients were satisfied with this information.

\section{Postoperative pain evaluation}

Pain intensity monitoring was prescribed for only $32.7 \%(621 / 1900)$ of cases (table 3$)$. However, written postoperative pain evaluation was frequent in surgical wards $(93.7 \%$ (1778/1898), at intervals of 4.1 hours (4.0) and was noted more frequently on a specific document dedicated to pain monitoring $(78.3 \%(1381 / 1764)$ than on nursing records $(55.1 \%$ (974/1767). Evaluation tools were not standardized, with a numerical scale (NS) used most frequently. Written pain score was available as a criterion for recovery room discharge for only $19.8 \%(363 / 1834)$ of patients.

\section{Pain intensity}


Data for pain intensity before and after surgery are listed in table 4. Preoperative pain was reported at the site of surgery in $62.7 \%$ (470/750) of patients. This preoperative pain, when present, had existed for more than a year in $35.6 \%$ (168/472) of patients. Patients reporting preoperative pain had significantly more intense postoperative pain at rest (ANOVA, $\mathrm{p}=0.0002$ ) and when moving (ANOVA, $\mathrm{p}=0.001$ ) than patients without preoperative pain. Mean postoperative numerical pain score for all patients, at the time of the auditor's visit, was 2.7 (1.3) at rest and 4.9 (1.9) during movement, with a maximal level of 6.4 (2.0) during the first 24 hours after surgery. Severe pain was present in $4.2 \%(71 / 1680)$ of patients at rest, $26.9 \%(452 / 1680)$ of patients during movement and maximal pain since surgery was severe in $50.9 \%(855 / 1680)$ of patients.

\section{$\underline{\text { Analgesics }}$}

The analgesics administered during surgery are listed in table 5. Analgesics were administered intraoperatively in $63.6 \%$ (1207/1898) of patients. Non opioid analgesics, including paracetamol (82.3\% (983/1194)), ketoprofen $(39.6 \%(472 / 1193))$ and nefopam (24.2\% (288/1192) $\left(\right.$ Acupan ${ }^{\circledR}$ Biocodex, Paris France)), were frequently used during surgery. Intraoperative opioids were used less frequently than non opioid analgesics. The opioid analgesics used were intravenous infusions of tramadol (11.5\% (137/1193)), morphine $(14.1 \%(168 / 1191))$ or subarachnoid morphine $(4.9 \%(58 / 1191))$ at a low dose (98 micrograms (1156)). Ketamine was used as an intraoperative antihyperalgesic (9.2\% $(110 / 1198))$. Regional anesthesia, in the form of an intraoperative infiltration (1.3\% $(16 / 1191))$, epidural $(1.4 \%(17 / 1191))$ or peripheral nerve blocks $(6.7(80 / 1191))$ was rarely used during surgery.

\section{Information about pain treatment organization}

Information about the general organization of postoperative pain treatment is provided in table 6. Analgesics were prescribed for $98.2 \%(1670 / 1701)$ of patients. Most $(89 \%(315 / 354))$ of the patients requesting rescue analgesics (18.8\% (354/1885) received such treatment within 15 minutes. However, most patients waited until they were in intense pain before requesting rescue analgesia $(94.5 \%(335 / 354))$. Using a numerical scale from 0 to 10 , 
patients reported high levels of pain relief $(7.9(1.5))$ and satisfaction $(9.2(0.8))$ with pain management. Written evidence of analgesic prescription before painful procedures was rarely found on the patient's chart $(0.1 \%(2 / 1868)$. No protocol for postoperative pain management was found for $25.9 \%(492 / 1900)$ of the patients. Pain treatment was rarely $(17 \%(323 / 1900))$ adapted between surgery and the auditor's visit. Acute pain teams were available at only $14.5 \%$ of centers. The presence of an acute pain team was associated with greater use of written documents for informing patients $(71 \%$ versus $59 \% ; p=0.002)$, the recording of this information being delivered on the patient's chart $(18 \%$ versus $13 \%, p=$ 0.03 ) and use of pain score as an RR discharge criterion (20\% versus $14 \% ; p=0.007)$. A postoperative pain quality program was available at $72.4 \%$ of centers. It was not associated with increases in any other indices of postoperative pain management quality.

\section{Opioids}

The details of opioid prescriptions are given in table 7. Morphine was administered to $62.1 \%$ of patients, mostly subcutaneously $(35.1 \%$ (549/1564)), via patient-controlled analgesia (PCA; $21.4 \%(334 / 1562))$ or orally $(5.6 \%(107 / 1899))$. Morphine PCA was most frequently used after visceral $(25.8 \%(86 / 334), p=0.005)$, thoracic $(55 \%(11 / 20, p=0.0009)$ and gynecologic surgery $(30.7 \% 43 / 140, p=0.006)$. Continuous intravenous morphine infusions were occasionally prescribed either alone $(0.5 \%(9 / 1900)$ or in combination with PCA morphine $(0.5 \%$ (10/1900). Subcutaneous morphine was administered regularly in $33.7 \%$ $(186 / 549)$ of patients receiving this treatment. Individual doses of $10 \mathrm{mg}$ were prescribed in $44.6 \%(240 / 537)$ of cases. Doses were separated by four hours for only $28.2 \%(147 / 523)$ of prescriptions. Subcutaneous morphine prescriptions were respected by the nurses in $63.7 \%$ (304/477) of cases. The criteria for subcutaneous morphine administration on demand were non specific in $53 \%$ of cases and based on a numerical pain score in the other $47 \%$. The use of a non specific criterion was associated with a higher frequency of severe maximal pain $(E N \geq 7)$ described by the patient $\left(\chi^{2}, p<0.03\right)$. Other prescribed opioids included, in descending order of frequency, tramadol (15.2\%), nalbuphine (11.5\%), dextropropoxyphene (6.3\%), codeine (3.3\%) and buprenorphine (1.2\%). Tramadol was administered at doses and 
intervals conforming to recommendations. Tramadol prescriptions were frequently respected by nurses $(83.3 \%(236 / 283))$.

\section{Non opioid analgesics}

Non opioid analgesics (table 8) were frequently used (95.5\% (1806/1891)): paracetamol (90.3\% (1715/1900)), ketoprofen (48.5\% (922/1900)) and nefopam (21.4\% (407/1900)). Paracetamol was combined with PCA and subcutaneous morphine in 95.2\% (317/333) and $95.8 \%(523 / 546)$ of cases, respectively. Ketoprofen was combined with PCA and subcutaneous morphine in $54.4 \%(181 / 333)$ and $52.2 \%(285 / 546)$ of cases, respectively. Nefopam was combined with PCA and subcutaneous morphine in 29.1\% (97/333) and $20.1 \%(110 / 546)$ of cases, respectively. Two non opioid analgesics were combined with morphine PCA and subcutaneous morphine in $15.3 \%(51 / 333)$ and $22.7 \%$ of treated patients (124/546), respectively. PCA morphine was combined with paracetamol-ketoprofen (8.8\%), paracetamol-nefopam (4.6\%) and nefopam-ketoprofen (1.8\%). Subcutaneous morphine was combined with paracetamol-ketoprofen (14.9\%), nefopam-ketoprofen (5.7\%) and paracetamol-nefopam (2\%). Three non-opioid analgesics were combined with PCA and subcutaneous morphine in $1.8 \%(7 / 333)$ and $1.8 \%(10 / 546)$ of treated patients, respectively. These non opioid drugs were frequently prescribed with a regular schedule and prescription was respected by nurses. Ketoprofen was the most frequent NSAID prescribed (99\%), at doses and intervals in accordance with recommendations. Ketamine $(0.7 \%)$ and parecoxib $(1.8 \%)$ were rarely prescribed after surgery. Continuous regional anesthetic techniques were rarely used for postoperative pain control, with only $1.5 \%(28 / 1892)$ of patients having epidural and 4.7\% (89/1889) peripheral nerve blocks. Lumbar epidural and femoral nerve blocks with continuously administered ropivacaine were the most frequent. Epidural analgesia was mainly used in visceral $(2.6 \%, 10 / 381$, not significant in comparisons with other types of surgery) and thoracic surgery (17.4\%, 4/23, $p=0.0001$ versus other type of surgery). Epidural analgesia was used in 5.4\% (2/37) of patients undergoing colectomy. Continuous postoperative peripheral nerve block was used in $15.4 \%$ (88/570) of patients 
undergoing orthopedic surgery. Peripheral nerve block was used in $43 \%$ ( $n=54 ; 9.5 \%$ of orthopedic patients) of patients undergoing total knee arthroplasty.

\section{$\underline{\text { Side effects }}$}

The side effects (SE) observed are listed in table 9. Written evaluations of SE were frequently found on patient's charts $(80.1 \%(1522 / 1900))$, and were more frequently found in a specific document $(72.4 \%(1095 / 1513)$ than in a nursing report $(55 \%(832 / 1513))$. Monitoring (49\% (931/1900)) and management $(56.3 \%(1070 / 1900))$ of SE were not frequently prescribed. Specific scores were rarely used for SE evaluation (26.8\% (404/1508). Protocols for SE management were found for $53.3 \%$ of patients (408/776). The global incidence of SE was similar for information provided by the patient $(26.4 \%(498 / 1888))$ and written monitoring data from the patient's chart $(25.1 \%(378 / 1505))$. These side effects had a significant impact on the patient, as reflected by numerical scale scores for intensity $(4.7$ (1.2)). Postoperative nausea and vomiting were the most frequent side effects. The incidence of sedation, pruritus, urinary retention and motor block as estimated by the patient differed from that estimated from monitoring by nurses.

\section{Discussion (1382 words)}

This is the first national survey providing reliable information about postoperative pain (POP) management in France. It reveals significant improvements in terms of pain intensity, the reporting of pain in medical files, and the prescription of PCA morphine and combination of analgesics. However, preoperative patient information and evaluation, pain evaluation protocols, subcutaneous morphine use, the use of regional anesthesia, acute pain team development and quality improvement programs remain to be improved.

Most previous national surveys on POP control have been based on postal questionnaires sent to professionals $[6,15,36,37,44,45,53]$. In such studies, there is a risk of overestimation of professional practice and the patient remains an expert witness of care quality. Our patient-based results therefore provide a reliable nationwide evaluation of POP 
management. We also stratified all French surgical centers according to institutional and activity level criteria and then constituted a representative sample, by random sampling within each stratum. The distribution of surgical specialties in our survey was similar to that reported in 1996, with orthopedic, visceral and gynecologic/obstetric surgery most frequent [17]. Our survey was carried out by a single trained auditor, maximizing data homogeneity. However, it was subject to several limitations. Data were obtained only for the first day after inpatient surgery in adult patients. We therefore have no information for pediatric patients or patients undergoing day surgery. We also have no information for later times, when a gap has been reported to open up between initial intensive analgesia and oral analgesics [60], or for persistent pain [47]. The survey was performed over 24 months, during which time practices may have changed. We also have no information about SE management.

Between 1973 and 1999, the incidence of moderate-severe POP decreased significantly, by $1.9 \%$ per year (1.1-2.7\%) [27]. Accordingly, comparison with the largest previous patientbased survey on POP control in France [48] showed that the incidence of severe pain at rest decreased from $46.3 \%$ to $4.2 \%$ between 1996 and 2007 . Our results also compare favorably with recent reports, with similar results for the incidence of severe POP at rest $(1-5 \%)$ reported in 1998 by Harmer et al. [33], and higher incidences reported in 2002 by Dolin et al. [27] (10.9\%) and 2003 by Apfelbaum et al. (i.e. 47\%) [3]. Mean maximal numerical pain score in the first 24 hours in previous studies was lower (3.7-4.8) [4] or higher (6.8-7.1) than that in our survey [42]. This may be due to differences in both the surgical population and pain management. Overall, our results for POP intensity compare favorably with recent patient- and literature-based surveys.

There are several possible reasons for these improvements in POP management in France. The cornerstone of POP management is the regular evaluation of pain score and its reporting in the patient's file, making pain visible [55]. Our survey reveals a high frequency of pain reporting (>90\%) in surgical wards, comparing favorably with previous French surveys 
in 1996 (0\% reporting) [48] and 2000 (64-82\% reporting) [30], recent surveys in Germany (53.4\% reporting) [61], the United Kingdom (57\% reporting) [59] and a recent European declarative survey (44\% reporting) [8]. It has been suggested that educating nurses about pain and daily pain assessment with a numerical rating scale can improve the communication, assessment and documentation of patients' pain [23] and improve analgesic administration by nurses [24].

Our report also reveals an increase in morphine use, particularly via PCA, since 1996 (21.4\% versus $2 \%$ ) [48]. The optimal frequency of PCA use remains unclear, and the frequency of use varies considerably with type of surgery and survey but increases in PCA prescription is considered an improvement of pain management [31]. In a recent European declarative survey, PCA pumps were used by almost half the respondents after major orthopedic or abdominal surgery [8]. There is therefore probably room for improvement in France. Similarly, balanced analgesia may improve POP management [38]. We found that non opioid analgesics were more widely prescribed in France (95.5\%) than in a European survey in which intravenous non opioid drugs formed part of the first-line analgesic treatment after major surgery according to 64 to $72 \%$ of respondents (depending upon surgery type), and balanced analgesia use in more than $75 \%$ of patients was declared by $71 \%$ of respondents [8]. A combination of two non opioid analgesics with morphine may be considered optimal balanced analgesia [22]. Such a combination was observed for $15.3 \%$ of PCA and $22.7 \%$ of subcutaneous morphine prescriptions. This frequency cannot definitively be considered optimal, but suggests that physicians have understood the benefits of multimodal therapy.

This survey also reveals persistent limitations in POP management. One in three patients could not remember the information they were given concerning postoperative pain. Similar results have been published for the USA [3,42] and Spain [53]. Anesthesiologists in France must meet patients several days before surgery [21]. This facilitates the delivery of information about pain control, as shown by the higher frequency of preoperative information than in other European countries [8]. Information was mostly provided orally and was rarely 
reported on the patient's chart. Efforts should be made to define the optimal organization of preoperative patient information. The high incidence of chronic preoperative pain at the site of surgery is surprising. Our survey, like previous reports [47], suggests that preoperative pain leads to greater POP, but other factors may be involved. We think anesthesiologists should collect information about preoperative pain as a factor predictive of POP [47].

Pain evaluation before $R R$ discharge remains insufficient. This factor has been identified as predictive of pain control quality [49] and is used for the professional evaluation of French anesthesiologists [57]. A more standardized tool for POP evaluation should be used in surgical wards. The NS has the advantage of clinical validity and simplicity [25]. The VAS requires equipment and the precision of the measure has no clinical significance [16]. Pain should be assessed and reported in the patient's file on movement (3.6\% in our survey) and after treatment (1.4\% in our survey). Similar inadequacies of pain evaluation on movement have been reported in other European countries [8].

The widespread use of subcutaneous morphine suggests that education and rationalization are required to improve the quality of prescription. Nurses only partly respected opioid prescription, and this has been shown to be predictive of poor pain control $[24,49]$. We also identified an association between non numerical criteria for morphine administration on demand and higher maximal pain score. This confirms the importance of a clear protocol for pain evaluation and treatment, particularly for opioid analgesia on demand.

The limited use of regional anesthetic techniques for pain control was disappointing. It first resulted from the low frequency of use of intraoperative infiltration techniques. Furthermore, $43 \%$ of patients scheduled for total knee arthroplasty received peripheral nerve block analgesia and $5.4 \%$ patients scheduled for colectomy received continuous epidural analgesia. This frequency of use is insufficient, although a clear improvement has occurred since 1996, when postoperative continuous regional anesthesia was not used at all [48]. A recent declarative European survey also reported that peripheral nerve blocks were the firstline treatment for $53 \%$ of patients undergoing major orthopedic surgery [8]. However, recent 
declarative $[8,15,53,61]$ or patient-based [42] surveys have described much higher frequencies of epidural analgesia use (> 60\%). This limited use of epidural analgesia may have contributed to the high maximal pain score obtained in our survey and does not facilitate the development of rehabilitation programs [9,58]. The reasons for this limited use may include higher risks [12], medical and legal concerns, insufficient reimbursement, insufficient training of anesthesiologists [10] and organizational difficulties.

The organization of the centers was assessed by direct observation and interview of the professionals. Evaluation and treatment protocols, which help to improve pain control [33], were lacking for $37 \%$ and $26 \%$ of patients, respectively. Acute pain teams and pain quality programs were not available at $85 \%$ and $28 \%$ of audited centers, respectively. Acute pain teams seem to be more frequent in declarative surveys (32-63\%), particularly in large hospitals $[15,36,53,54]$. As previously reported [42], our analysis suggests that presence of acute pain teams is associated with other improvements in pain management organization.

The results of this survey should facilitate the development of revised POP control guidelines, 10 years after publication of the previous guidelines. They should facilitate the definition of target groups and the tailoring of the required changes to these groups. 


\section{Acknowledgments}

We would like to thank all the surgical centers that participated in this survey, and particularly members of the anesthesia, surgical and administrative departments of these centers.

We would also like to thank the members of the Pain and Regional Anesthesia Committee of the French Anesthesia and Intensive Care Society: Anissa Belbachir, Gille Boccara, Francis Bonnet, Hervé Bouaziz, Olivier Choquet, Jean Pierre Estebe, Régis Fuzier, Elizabeth Gaertner, Olivier Gall, Christian Jayr, Denis Jochum, Hawa Keita Meyer, Xavier Paqueron, Jacques Ripart. Thanks are also due to Alain Beauchet, Louis Brasseur, Marcel Chauvin, Marc Gentili, François Larue and Henry McQuay for helpful advice during the preparation of this study and assistance with the writing of the manuscript.

\section{Fundings}

This survey was supported by a grant of 100000 euros of the Caisse Nationale de Prevoyance (CNP) foundation and a 50000 euros grant of the French Anesthesia and Intensive Care Society

Authors have no competing interests 


\section{References}

[1] Abbott FV, Gray-Donald K, Sewitch MJ, Johnston CC, Edgar L, Jeans ME. The prevalence of pain in hospitalized patients and resolution over six months. Pain 1992;50:15-28.

[2] Allvin R, Brasseur L, Crul B, Dahl J, Lehmann K, Nicosia F. European minimum standards for the management of postoperative pain. Europain Task Force. UK Pegasus Healthcare Intl, 1998.

[3] Apfelbaum JL, Chen C, Mehta SS, Gan TJ. Postoperative pain experience: results from a national survey suggest postoperative pain continues to be undermanaged. Anesth Analg 2003;97:534-40.

[4] Atkinson L, Bogduk N, Cousins MJ. Management of severe pain. Australian Government Publishing Service. Canberra Australia, 1988.

[5] Aubrun F, Langeron O, Quesnel C, Coriat P, Riou B. Relationships between measurement of pain using visual analog score and morphine requirements during postoperative intravenous morphine titration. Anesthesiology 2003;98:1415-21.

[6] Austin J. Provision of postoperative epidural services in NHS hospitals. Anesthesia 2002;57:778-84.

[7] Bardiau FM, Taviaux NF, Albert A, Boogaerts JG, Stadler M. An intervention study to enhance postoperative pain management. Anesth Analg 2003;96:179-85.

[8] Benhamou D, Berti M, Brodner G, De Andres J, Draisci G, Moreno-Azcoita M, Neugebauer EAM, Schwenk W, Torres LM, Viel E. Pain 2007, Postoperative Analgesic THerapy Observational Survey (PATHOS): A practice pattern study in 7 Central/Southern European countries, in press.

[9] Block BM, Liu SS, Rowlingson AJ, Cowan AR, Cowan JA, Jr. Wu CL. Efficacy of postoperative epidural analgesia: a meta-analysis. Jama 2003;290:2455-63.

[10] Bouaziz H, Mercier FJ, Narchi P, Poupard M, Auroy Y, Benhamou D. Survey of regional anesthetic practice among French residents at time of certification. Reg Anesth 1997;22:218-22.

[11] Brasseur L, Larue F, Charpak Y. Postoperative analgesia in France. A study of the prescribing doctor's approach. Presse Med 1992;21:463-7.

[12] Brull R, McCartney CJ, Chan VW, El-Beheiry H. Neurological complications after regional anesthesia: contemporary estimates of risk. Anesth Analg 2007;104:965-74.

[13] Bruster S, Jarman B, Bosanquet N, Weston D, Erens R, Delbanco TL. National survey of hospital patients. Bmj 1994;309:1542-6.

[14] Carr DB, Goudas LC. Acute pain. Lancet 1999;353:2051-8. 
[15] Carr DB, Miaskowski C, Dedrick SC, Williams GR. Management of perioperative pain in hospitalized patients: a national survey. J Clin Anesth 1998;10:77-85.

[16] Cepeda MS, Africano JM, Polo R, Alcala R, Carr DB. What decline in pain intensity is meaningful to patients with acute pain? Pain 2003;105:151-7.

[17] Clergue, F, Auroy Y, Pequignot F, Jougla E, Lienhart A, Laxenaire MC. French survey of anesthesia in 1996. Anesthesiology 1999;91:1509-20.

[18] Code de la santé Publique. Article R1112-4.

http://www.legifrance.gouv.fr/WAspad/UnArticleDeCode?commun=CSANPU\&art=L1112 -4 .

[19] Code de la santé Publique. Article R4311-5.

http://www.legifrance.gouv.fr/WAspad/UnArticleDeCode?commun=CSANPU\&art=R4311 $-5$

[20] Code de la Santé Publique. Loi no 2005-370 du 22 avril 2005 art. 1, art. 2 Journal Officiel du 23 avril 2005.

http://www.legifrance.gouv.fr/WAspad/UnArticleDeCode?commun=CSANPU\&art=L1110 $-5$

[21] Code la Santé Publique. Article D6124-91.

http://www.legifrance.gouv.fr/WAspad/UnArticleDeCode?commun=CSANPU\&art=D6124 $-91$.

[22] Curatelo M, Sveticic G. Drug combinations in pain treatment: a review of the published evidence and a method for finding the optimal combination. Best Practice and Res Clin Anaesthesiol 2002;4:507.

[23] de Rond ME, de Wit R, van Dam FS, Muller MJ. A pain monitoring program for nurses: effects on communication, assessment and documentation of patients' pain. J Pain Symptom Manage 2000;20:424-39.

[24] de Rond, ME, de Wit R, van Dam FS, Muller MJ. A Pain Monitoring Program for nurses: effect on the administration of analgesics. Pain 2000;89:25-38.

[25] DeLoach LJ, Higgins MS, Caplan AB, Stiff JL. The visual analog scale in the immediate postoperative period: intrasubject variability and correlation with a numeric scale. Anesth Analg 1998;86:102-6.

[26] Desbiens NA, Wu AW. Pain and suffering in seriously ill hospitalized patients. J Am Geriatr Soc 2000;48:S183-6.

[27] Dolin CJ, Cashman JN, Bland JM. Effectiveness of acute postoperative pain management: I. Evidence from published data. Br J Anaesth 2002;89:409.

[28] Donovan, M, Dillon P, McGuire L. Incidence and characteristics of pain in a sample of medical-surgical inpatients. Pain 1987;30:69-78. 
[29] Edwards, P, Roberts I, Clarke M, DiGuiseppi C, Pratap S, Wentz R, Kwan I. Increasing response rates to postal questionnaires: systematic review. Bmj 2002;324:1183.

[30] Galinski M, Fletcher D, Gaude V, Guirimand F, Chauvin M. Periodic evaluation of practices in postoperative pain management. Ann Fr Anesth Reanim 2000;19:725-33.

[31] Gordon DB, Dahl JL. Quality improvement challenges in pain management. Pain 2004; 107: 1-4.

[32] Gould TH, Crosby DL, Harmer M, Lloyd SM, Lunn JN, Rees GA, Roberts DE, Webster JA. Policy for controlling pain after surgery: effect of sequential changes in management. Bmj 1992;305:1187-93.

[33] Harmer M, Davies KA. The effect of education, assessment and a standardised prescription on postoperative pain management. The value of clinical audit in the establishment of acute pain services. Anesthesia 1998;53:424-30.

[34] Holmstrom B, Rawal N, Arner S. The use of central regional anesthesia techniques in Sweden: results of a nation-wide survey. Swedish Association of Anesthesia and Intensive care. Acta Anaesthesiol Scand 1997;41:565-72.

[35] Horvitz DG, Thompson DJ. A generalization of sampling without replacement from a finite universe. J Am Stat Assoc 1952;47:663-685.

[36] Kampe S, Kiencke P, Krombach J, Cranfield K, Kasper SM, Diefenbach C. Current practice in postoperative epidural analgesia: a german survey. Anesth Analg 2002;95:1767-9.

[37] Karling M, Renstrom M, Ljungman G. Acute and postoperative pain in children: a Swedish nationwide survey. Acta Paediatr 2002;91:660-6.

[38] Kehlet H. Postoperative opioid sparing to hasten recovery. What are the issues ? Anesthesiology 2005;102:1083.

[39] Larue F, Fontaine A, Brasseur L. Evolution of the French public's knowledge and attitudes regarding postoperative pain, cancer pain, and their treatments: two national surveys over a six-year period. Anesth Analg 1999;89:659-64.

[40] LOI n²002-303 du 4 mars 2002 relative aux droits des malades et à la qualité du système de santé.

http://www.legifrance.gouv.fr/WAspad/UnTexteDeJorf?numjo=MESX0100092L.

[41] Marks RM, Sachar EJ. Undertreatment of medical inpatients with narcotic analgesics. Ann Intern Med 1973;78:173-81.

[42] Miaskowski C, Crews J, Ready LB, Paul SM, Ginsberg B. Anesthesia-based pain services improve the quality of postoperative pain management. Pain 1999;80:23-9.

[43] Neugebauer E, Wulf $\mathrm{H}$. Recommendations and guidelines for perioperative pain therapy in Germany. Langenbecks Arch Chir Suppl Kongressbd 1998;115:666-71. 
[44] Neugebauer E, Sauerland S, Keck V, Simanski C, Witte J. Surgical pain management. A Germany-wide survey including the effect of clinical guidelines. Chirurg 2003;74:235-8.

[45] Nolli M, Apolone G, Nicosia F. Postoperative analgesia in Italy. National survey on the anaesthetist's beliefs, opinions, behaviour and techniques in postoperative pain control in Italy. Acta Anaesthesiol Scand 1997;41:573-80.

[46] Pazart LH, Mattilon Y, Massol J. Problems with guidelines. Clinical practice must be taken into account when guidelines are drawn up. Bmj 1997;314:518-9.

[47] Perkins FM, Kehlet $\mathrm{H}$. Chronic pain as an outcome of surgery. A review of predictive factors. Anesthesiology 2000;93:1123-33.

[48] Poisson-Salomon AS, Brasseur L, Lory C, Chauvin M, Durieux P. Audit of the management of postoperative pain. Presse Med 1996;25:1013-7.

[49] Poisson-Salomon AS, De Chambine S, Lory C. Patient-related factors and professional practices associated with postoperative pain. Rev Epidemiol Sante Publique 2005;53 Spec No 1:1S47-56.

[50] Practice guidelines for acute pain management in the perioperative setting. A report by the American Society of Anesthesiologists Task Force on Pain Management, Acute Pain Section. Anesthesiology 1995;82:1071-81.

[51] Prise en charge de la douleur postopératoire chez l'adulte et l'enfant. Conférence de consensus. Texte court. http://www.sfar.org/douleurpostopccons.html.

[52] Projet COMPAQH. http://ifr69.vjf.inserm.fr/compaqh/indic/indic19.html

[53] Puig MM, Montes A, Marrugat J. Management of postoperative pain in Spain. Acta Anaesthesiol Scand 2001;45:465-70.

[54] Rawal N, Allvin R. Acute pain services in Europe: a 17-nation survey of 105 hospitals. The EuroPain Acute Pain Working Party. Eur J Anaesthesiol 1998;15:354-63.

[55] Rawal, N and Berggren L. Organization of acute pain services: a low-cost model. Pain 1994;57:117-23.

[56] Ready LB, Oden R, Chadwick HS, Benedetti C, Rooke GA, Caplan R, Wild LM. Development of an anesthesiology-based postoperative pain management service. Anesthesiology 1988;68:100-6.

[57] Référentiel de pratiques professionnelles. Prise en charge de la douleur postopératoire. http://62.160.224.228/telechargement/4008456306/6609.pdf?bcsi_scan_F6BB18401801 7D9D=0\&bcsi_scan_filename=6609.pdf.

[58] Richman JM, Liu SS, Courpas G, Wong R, Rowlingson AJ, McGready J, Cohen SR, Wu CL. Does continuous peripheral nerve block provide superior pain control to opioids? A meta-analysis. Anesth Analg 2006;102:248-57. 
[59] Roberts GC. Post-craniotomy analgesia: current practices in British neurosurgical centres-a survey of post-craniotomy analgesic practices. Eur J Anaesthesiol 2005;22: 328

[60] Smith G, Power I. Audit and bridging the analgesic gap. Anesthesia 1998;53:521-2.

[61] Stamer UM, Mpasios N, Stuber F, Maier C. A survey of acute pain services in Germany and a discussion of international survey data. Reg Anesth Pain Med 2002;27:125

[62] Strohbuecker B, Mayer H, Evers GC, Sabatowski R. Pain prevalence in hospitalized patients in a German university teaching hospital. J Pain Symptom Manage 2005;29:498-506.

[63] The Royal College of Surgeons of England. The College of Anaesthetists. Commission on the provision of surgical services. Report of the working party on pain after surgery september 1990.

[64] Warszawski J, Lellouch J. Méthodes d'estimation dans une enquête par sondage. Rev Epidemiol Santé Publique 1997;45:150-168. 
Table 1: Patients and surgery characteristics

\begin{tabular}{|c|c|}
\hline Sex, percentage of men (\%) & $45.5(858 / 1885)$ \\
\hline Age (year) & $55.9(12.7)$ \\
\hline $\begin{array}{l}\text { Time between the start of surgery and the auditor's visit } \\
\text { (hour) }\end{array}$ & $24(3.1)$ \\
\hline \begin{tabular}{ll}
\multicolumn{2}{l}{ Type of surgery (\%) } \\
- & Orthopaedic \\
- & Visceral \\
- & Gynaecology / obstetric \\
- & Cardiac and vascular \\
- & Urology \\
- & ENT and stomatology \\
- & Neurosurgery \\
- & Thoracic surgery \\
- & Other
\end{tabular} & $\begin{array}{c}29.9(564 / 1887) \\
22(415 / 1887) \\
14.3(264 / 1887) \\
9.2(174 / 1887) \\
7.4(140 / 1887) \\
4.8(91 / 1887) \\
3.8(72 / 1887) \\
1.2(23 / 1887) \\
7.5(142 / 1887)\end{array}$ \\
\hline $\begin{array}{c}\text { Duration of surgery }(\%) \\
-\quad<1 \text { hour } \\
-\quad 1-2 \text { hours } \\
-\quad>2 \text { hours }\end{array}$ & $\begin{array}{l}18.1(340 / 1876) \\
50.7(951 / 1876) \\
31.2(585 / 1876)\end{array}$ \\
\hline Elective surgery (\%) & $95.4(1810 / 1897)$ \\
\hline $\begin{array}{cl}\text { Type of anesthesia (\%) } \\
\text { - } & \text { General anesthesia } \\
\text { - } & \text { Epidural anesthesia } \\
- & \text { Spinal anesthesia } \\
- & \text { Peripheral nerve block } \\
- & \text { Sedation } \\
- & \text { Local anesthesia }\end{array}$ & $\begin{array}{c}79.2(1504 / 1899) \\
1.3(25 / 1899) \\
13.8(262 / 1899) \\
9.9(188 / 1899) \\
2.7(51 / 1899) \\
2.9(55 / 1899)\end{array}$ \\
\hline
\end{tabular}

ENT: ear, nose and throat surgery 
Table 2: Preoperative information about postoperative pain

\begin{tabular}{|l|c|}
\hline Information remembered by the patient (\%) & $69.3(1315 / 1897)$ \\
\hline Patient satisfied with preoperative information (\%) & $95.3(1251 / 1313)$ \\
\hline For patients who remembered the information they were given & $90.3(1190 / 1318)$ \\
$-\quad$ Oral information recalled by the patient (\%) & $60.6(794 / 1310)$ \\
$-\quad$ Written information recalled by the patient (\%) & $36.3(689 / 1898)$ \\
\hline Information noted as delivered on the patient's chart (\%) & $18.2(346 / 1899)$ \\
\hline Postoperative analgesic protocol noted on the patient's chart (\%) & $20.1(382 / 1900)$ \\
\hline Contract on pain control noted on the patient's chart (\%) & $4.4(83 / 1896)$ \\
\hline Patient asked to notify pain (\%) & $95.9(1816 / 1894)$ \\
\hline
\end{tabular}


Table 3: Evaluation of postoperative pain

\begin{tabular}{|c|c|}
\hline Postoperative pain evaluation prescribed (\%) & $32.7(621 / 1900)$ \\
\hline $\begin{array}{l}\text { In the absence of pain evaluation prescription, protocols available for } \\
\text { postoperative pain evaluation (\%) (\%) }\end{array}$ & $63.4(795 / 1254)$ \\
\hline At least one written evaluation in the recovery room (\%) & $55.2(1049 / 1900)$ \\
\hline At least one written evaluation in the surgical ward (\%) & $93.7(1778 / 1898)$ \\
\hline $\begin{array}{l}\text { If written evaluation carried out, frequency of multiple evaluations (\%) } \\
\text { - } \quad \text { According to the patient's chart } \\
\text { - } \quad \text { According to the nurse }\end{array}$ & $\begin{array}{c}97(1723 / 1776) \\
100(1776 / 1776)\end{array}$ \\
\hline $\begin{array}{l}\text { Time between written pain evaluations (hour) } \\
\text { - } \quad \text { According to the patient's chart } \\
\text { - } \quad \text { According to the nurse }\end{array}$ & $\begin{array}{l}4.1(4.0) \\
2.1(1.6)\end{array}$ \\
\hline $\begin{array}{l}\text { Document for written pain evaluation (\%) } \\
\text { - } \quad \text { Nursing report } \\
\text { - } \quad \text { Specific document dedicated to pain monitoring }\end{array}$ & $\begin{array}{l}55.1(974 / 1767) \\
78.3(1381 / 1764)\end{array}$ \\
\hline $\begin{array}{l}\text { Pain evaluation at rest (\%) } \\
\text { Pain evaluation on movement (\%) }\end{array}$ & $\begin{array}{c}100(1828 / 1828) \\
3.6(65 / 1810)\end{array}$ \\
\hline $\begin{array}{l}\text { Pain evaluation after analgesic administration (\%) } \\
\text { - } \quad \text { According to the patient's chart } \\
\text { - } \quad \text { According to the nurse }\end{array}$ & $\begin{array}{c}1.4(26 / 1829) \\
98.3(1796 / 1827)\end{array}$ \\
\hline $\begin{array}{l}\text { Pain score included in recovery room discharge criteria (\%) } \\
\text { - } \quad \text { No } \\
\text { - } \quad \text { Yes but not applied to the patient } \\
\text { - } \quad \text { Yes and applied to the patient }\end{array}$ & $\begin{array}{l}64.9(1190 / 1834) \\
15.4(282 / 1834) \\
19.8(363 / 1834)\end{array}$ \\
\hline 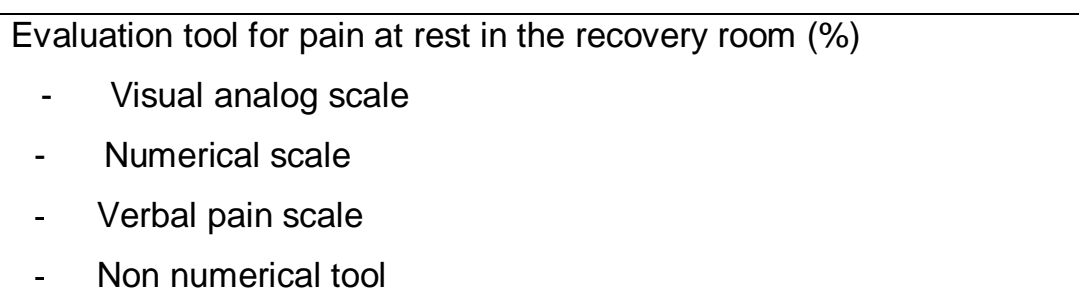 & $\begin{array}{l}21.4(222 / 1036) \\
43.3(449 / 1036) \\
18.5(192 / 1036) \\
16.7(173 / 1036)\end{array}$ \\
\hline 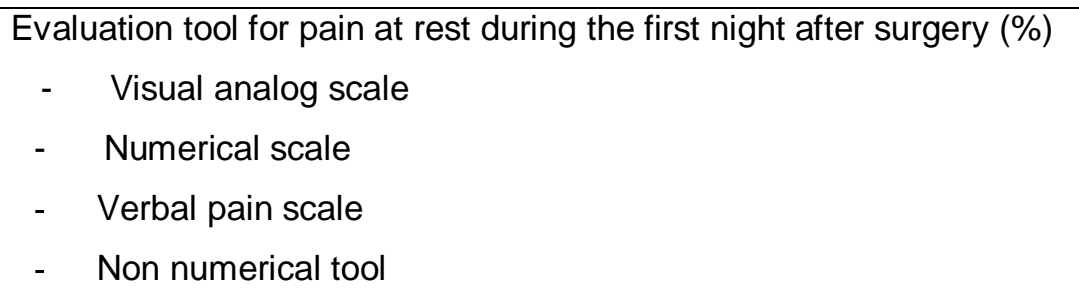 & $\begin{array}{l}19.7(327 / 1693) \\
41.3(699 / 1693) \\
13.8(234 / 1693) \\
25.3(428 / 1693)\end{array}$ \\
\hline 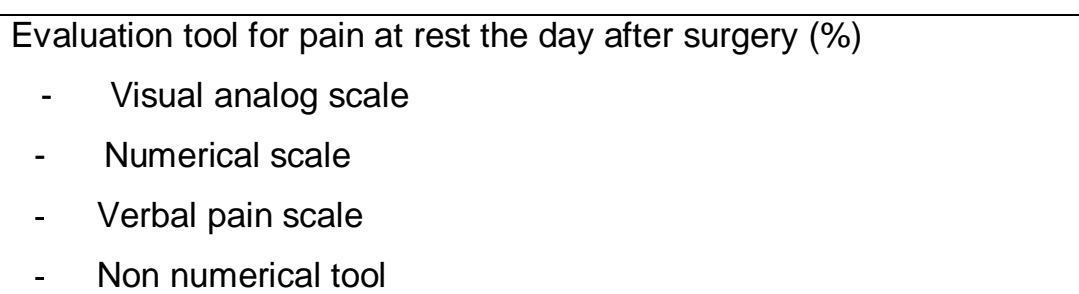 & $\begin{array}{l}21.1(299 / 1416) \\
41.2(583 / 1416) \\
13.8(195 / 1416) \\
24(340 / 1416)\end{array}$ \\
\hline
\end{tabular}


Table 4: Preoperative and postoperative pain intensity

\begin{tabular}{|c|c|}
\hline Frequency of preoperative pain at the surgical site (\%) & $62.7(470 / 750)$ \\
\hline Mean preoperative pain intensity at rest (NS) & $4.3(2.8)$ \\
\hline Mean preoperative pain intensity on movement (NS) & $6.4(2.2)$ \\
\hline Frequency of preoperative pain for more than one year (\%) & $35.6(168 / 472)$ \\
\hline Global frequency of postoperative pain since surgery (\%) & $88.6(1672 / 1887)$ \\
\hline $\begin{array}{ll}\text { For all patients with postoperative pain } \\
\text { - } & \text { Frequency of continuous pain (\%) } \\
\text { - } & \text { Frequency of intermittent pain (\%) } \\
\text { - } & \text { Frequency of pain at rest (\%) } \\
\text { - } & \text { Frequency of pain on movement (\%) } \\
\text { - } & \text { Intensity of pain at rest at the time of auditor's visit (NS) } \\
\text { - } & \text { Intensity of pain on movement at the time of auditor's visit (NS) } \\
\text { - } & \text { Intensity of maximal pain since surgery (NS) } \\
\text { - } & \text { Severe pain at rest (\%) (NS } \geq 7) \\
\text { - } & \text { Severe pain on movement (\%) (NS } \geq 7) \\
\text { - } & \text { Severe pain as maximal pain since surgery (\%) (NS } \geq 7) \\
\text { - } & \text { Maximal written pain score during the first night after surgery (NS) } \\
\text { - } & \text { Maximal written pain score in the recovery room (NS) } \\
\text { - } & \text { Maximal written pain score the day after surgery (NS) }\end{array}$ & $\begin{array}{c}64.6(1083 / 1677) \\
35.4(594 / 1677) \\
90.6(1519 / 1677) \\
99.6(1674 / 1677) \\
2.7(1.3)(n=1680) \\
4.9(1.9)(n=1680) \\
6.4(2.0)(n=1680) \\
4.2(71 / 1680) \\
26.9(452 / 1680) \\
50.9(855 / 1680) \\
2.8(2.5) \\
2.6(2.8) \\
1.8(2.2)\end{array}$ \\
\hline $\begin{array}{l}\text { For patients with or without preoperative pain (NS) } \\
\text { - Intensity of postoperative pain at rest for patient without preoperative pain } \\
\text { - } \\
\text { Intensity of postoperative pain on movement for patient without preoperative } \\
\text { - } \\
\text { - Intensity of maximal pain since surgery for patient without preoperative pain } \\
\text { - Intensity of pain at rest after surgery for patient with preoperative pain } \\
\text { - } \\
\text { - Intensity of pain on movement after surgery for patient with preoperative pain } \\
\text { Intensity of maximal pain since surgery for patient with preoperative pain }\end{array}$ & $\begin{array}{l}2.2(1.9)(n=240) \\
4.1(2.3)(n=240) \\
5.7(2.5)(n=240) \\
2.7(2.1)(n=427)^{\star *} \\
4.7(2.2)(n=427)^{\star} \\
6.0(2.3)(n=427)\end{array}$ \\
\hline
\end{tabular}

NS: numerical scale

${ }^{*} p=0.001 ;{ }^{* *} p=0.0002$; ANOVA for patients with preoperative pain versus patients without preoperative pain 
Table 5: Intraoperative analgesics

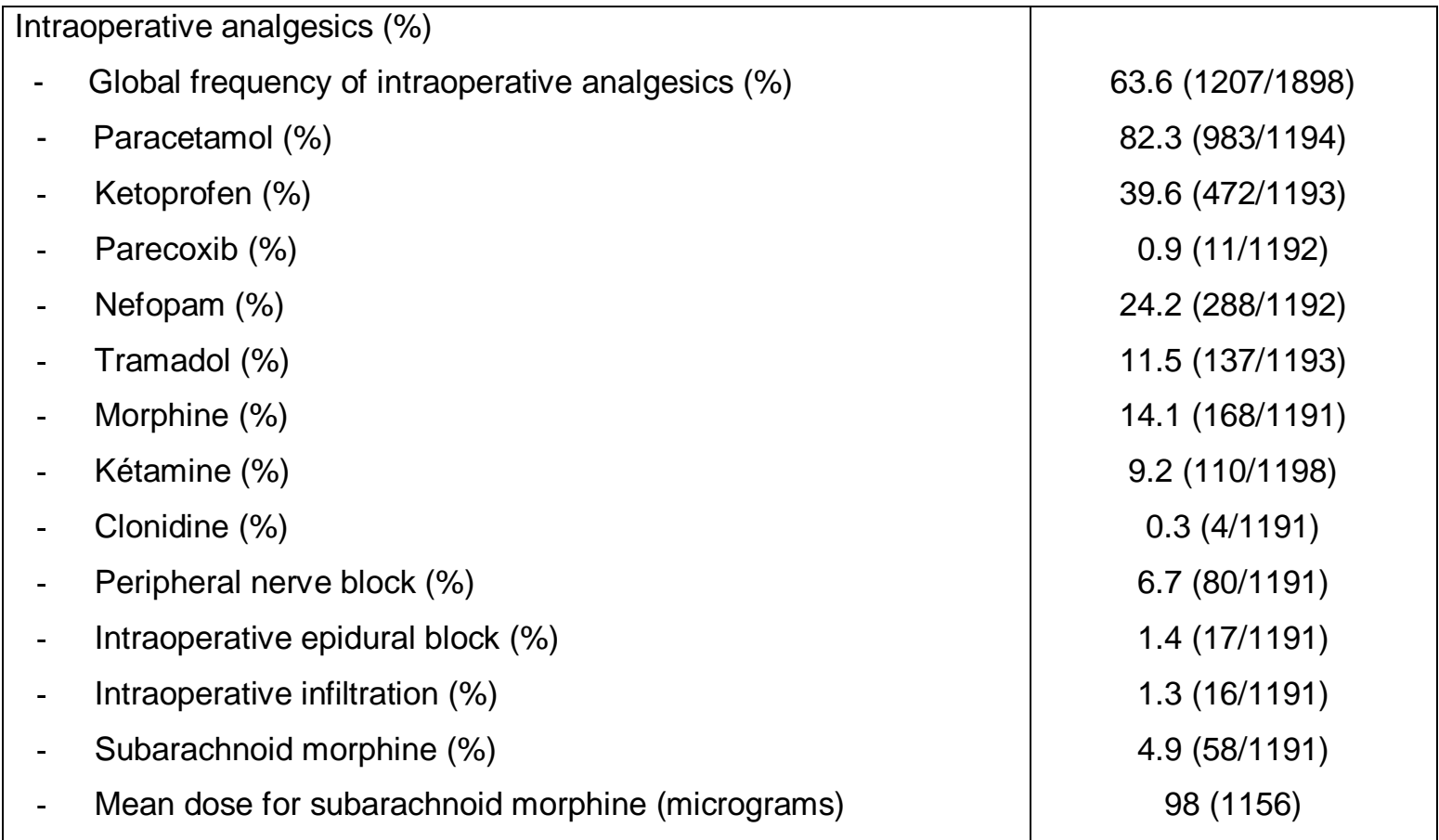


Table 6: General organisation of postoperative analgesia

\begin{tabular}{|l|c|}
\hline Global frequency of postoperative analgesia (\%) & $98.2(1670 / 1701)$ \\
\hline Frequency of rescue analgesia (\%) & $18.8(354 / 1885)$ \\
\hline $\begin{array}{l}\text { Frequency of patients requesting rescue analgesia when pain became too } \\
\text { intense (\%) }\end{array}$ & $94.5(335 / 354)$ \\
\hline Time to obtain rescue analgesia (\%) & \\
$-\quad<5 \mathrm{~min}$ & $71.2(252 / 354)$ \\
$-\quad<15 \mathrm{~min}$ & $17.8(63 / 354)$ \\
$-\quad 15-30 \mathrm{~min}$ & $2(7 / 354)$ \\
$-\quad 30-60 \mathrm{~min}$ & $1.2(4 / 354)$ \\
$-\quad>60$ min & $5.3(19 / 354)$ \\
\hline$\quad$ not administered & $2.5(9 / 354)$ \\
\hline Mean pain relief (NS) & $7.9(1.5)$ \\
\hline Mean patient satisfaction score (NS) & $9.2(0.8)$ \\
\hline$\quad \quad$ For staff behavior concerning postoperative pain treatment & $9.0(1.1)$ \\
\hline Written information about pain treatment before painful procedure (\%) & $0.1(2 / 1868)$ \\
\hline Frequency of protocols for postoperative pain treatment (\%) & $74.1(1408 / 1900)$ \\
\hline Frequency of adaptation of postoperative analgesics over 24 hours (\%) & $17(323 / 1900)$ \\
\hline Frequency of postoperative pain quality program (\% of centers) & $72.4 \%(55 / 76)$ \\
\hline Frequency of dedicated acute pain team (\% of centers) & $14.5 \%(11 / 76)$ \\
\hline
\end{tabular}

NS: numerical scale 
Table 7: Postoperative prescription of opioids

\begin{tabular}{|c|c|}
\hline Morphine treatment (\%) & $62.1(1180 / 1900)$ \\
\hline Mean morphine titration bolus (mg) & $2.6(1.2)$ \\
\hline Mean morphine titration interval (min) & $8.7(4.9)$ \\
\hline Morphine patient-controlled analgesia (PCA) prescribed (\%) & $21.4(334 / 1562)$ \\
\hline \multicolumn{2}{|l|}{ Analgesic for PCA } \\
\hline - Morphine (\%) & $88.6(296 / 331)$ \\
\hline - Morphine + ketamine (\%) & $11.4(46 / 331)$ \\
\hline Mean morphine PCA bolus (mg) & $1.2(1)$ \\
\hline Mean morphine PCA interval (min) & $9.5(8.0)$ \\
\hline Continuous morphine infusion with PCA (\%) & $0.5(10 / 1900)$ \\
\hline Continuous morphine infusion without PCA (\%) & $0.5(9 / 1900)$ \\
\hline Subcutaneous morphine (\%) & $35.1(549 / 1564)$ \\
\hline Systematic administration of subcutaneous morphine (\%) & $33.7(186 / 549)$ \\
\hline \multicolumn{2}{|l|}{ Interval for subcutaneous morphine administration (\%) } \\
\hline - 4 hours & $28.2(147 / 523)$ \\
\hline - 6 hours & $59.4(311 / 523)$ \\
\hline - 8 hours & $9.3(49 / 523)$ \\
\hline - 12 hours & $0.2(1 / 523)$ \\
\hline - None & $7.5(39 / 523)$ \\
\hline \multicolumn{2}{|l|}{ Dose of subcutaneous morphine (\%) } \\
\hline$-10 \mathrm{mg}$ & $44.6(240 / 537)$ \\
\hline$-5 \mathrm{mg}$ & $44.9(241 / 537)$ \\
\hline - Other & $11.4(61 / 537)$ \\
\hline Respect of subcutaneous morphine prescription by nurses (\%) & $63.7(304 / 477)$ \\
\hline Oral morphine (\%) & $5.6(107 / 1899)$ \\
\hline Frequency of tramadol / IV tramadol / systematic use of tramadol (\%) & $15.2 / 82.2 / 75.9$ \\
\hline Mean tramadol dose $(\mathrm{mg})$ and / interval $(\mathrm{h})$ & $140(133) / 8.9(8.3)$ \\
\hline Respect of tramadol prescription by nurses (\%) & $83.3(236 / 283)$ \\
\hline Frequency of buprenorphine / IV buprénorphine (\%) (n) & $1.2 / 29.6$ \\
\hline Frequency of nalbuphine (\%) (n) & $11.5(218)$ \\
\hline Frequency of dextropropoxyphene (\%) (n) & $6.3(117)$ \\
\hline Frequency of codeine (\%) (n) & $3.3(21)$ \\
\hline
\end{tabular}

Qualitative data are expressed as percentage.

Quantitative data are expressed as mean (SD).

PCA: patient controlled analgesia 
Table 8: Postoperative non opioid analgesics

\begin{tabular}{|c|c|c|}
\hline \multicolumn{2}{|c|}{ Non opioid analgesics } & \multirow{3}{*}{$95.5(1806 / 1891)$} \\
\hline- & Global frequency (\%) & \\
\hline \multicolumn{2}{|r|}{ Paracetamol } & \\
\hline & Frequency of use (\%) & $90.3(1715 / 1900)$ \\
\hline & Fixed schedule prescription (\%) & $98.2(1684 / 1715)$ \\
\hline & Respect of prescription by nurses (\%) & $94.3(1599 / 1696)$ \\
\hline & Mean paracetamol dosage (mg) and interval $(\mathrm{h})$ & $999(46) / 6.1(1.3)$ \\
\hline- & NSAID: use of ketoprofen / naproxen / ibuprofen / diclofenac (\%) & $99 / 0.2 / 0.2 / 0.6$ \\
\hline \multicolumn{3}{|c|}{ - Ketoprofen } \\
\hline & Frequency of use (\%) & $48.5(922 / 1900)$ \\
\hline & Fixed schedule prescription (\%) & $97.8(902 / 922)$ \\
\hline & Respect of prescription by nurses (\%) & $91.7(842 / 917)$ \\
\hline & Mean ketoprofen dose (mg) and interval (h) & $90(56) / 8.6(5.0)$ \\
\hline \multicolumn{3}{|c|}{ - Nefopam } \\
\hline & Frequency of use (\%) & $21.4(407 / 1900)$ \\
\hline & Fixed schedule prescription (\%) & $89.5(364 / 407)$ \\
\hline & Respect of prescription by nurses (\%) & $89.6(358 / 400)$ \\
\hline- & Frequency of parecoxib use (\%) (n) & $1.8(34)$ \\
\hline- & Frequency of celecoxib use (\%) & 0 \\
\hline- & Frequency of ketamine use (\%) (n) & $0.7(13)$ \\
\hline \multicolumn{3}{|c|}{ Postoperative continuous regional anesthetic techniques } \\
\hline & Epidural analgesia (\%) & $1.5(28 / 1892)$ \\
\hline- & Lumbar epidural / thoracic epidural (n) & $21 / 7$ \\
\hline- & Epidural analgesia based on ropivacaine / bupivacaine / sufentanil / morphine ( $\mathrm{n}$ ) & $22 / 3 / 6 / 2$ \\
\hline- & Modality of administration : continuous infusion / intermittent bolus / PCA (n) & $23 / 3 / 2$ \\
\hline- & Continuous nerve blocks (\%) & $4.7(89 / 1889)$ \\
\hline- & Femoral nerve block (\%) & 67.8 \\
\hline- & Interscalene block (\%) & 17.1 \\
\hline- & Sciatic block (\%) & 15.4 \\
\hline- & Posterior lumbar block (\%) & 2 \\
\hline- & Axillary block (\%) & 3.3 \\
\hline- & Nerve block uses ropivacaine / bupivacaine / lidocaine (\%) & $88.4 / 11.5 / 3$ \\
\hline- & Modality of administration: continuous infusion / intermittent bolus / PCA (\%) & 79.1/19.9/12.3 \\
\hline
\end{tabular}


Table 9: Side effects since surgery

Frequency of side effects evaluation (\%)

- According to the patient's chart

$80.1(1522 / 1900)$

- According to the nurse

$97.4(1851 / 1900)$

Document for written pain evaluation (\%)

- Nursing report

$55(832 / 1513)$

- Specific document for evaluation of side effect

$72.4(1095 / 1513)$

Monitoring of side effects is prescribed (\%)

$49(931 / 1900)$

Specific score to monitor side effects (SE) (\%)

$26.8(404 / 1508)$

Management of side effects is prescribed (\%)

$56.3(1070 / 1900)$

If no prescription of SE management, protocols available for SE management (\%)

$53.3(408 / 776)$

Global incidence of side effect according to

- The patient's chart (\%)

$25.1(378 / 1505)$

- $\quad$ The patient (\%)

Mean intensity of SE according to the patient (NS; 0: no SE, 10 unbearable SE)

$26.4(498 / 1888)$

$4.7(1.2)$

For patients with side effects

Incidence of PONV according to

- $\quad$ The patient (\%)

$83.3(417 / 501)$

- The patient's chart (\%)

$51.5(178 / 345)$

Incidence of sedation according to

- $\quad$ The patient (\%)

$11.5(57 / 492)$

- $\quad$ The patient's chart (\%)

$26.3(90 / 344)$

Incidence of urinary retention according to

- The patient (\%)

$3.0(15 / 492)$

- The patient's chart (\%)

$20.8(71 / 341)$

Incidence of constipation according to

- $\quad$ The patient (\%)

$0,2(1 / 492)$

- The patient's chart (\%)

$0(0 / 344)$

Incidence of pruritus according to

- $\quad$ The patient (\%)

$6.5(32 / 492)$

- The patient's chart (\%)

$2.1(7 / 344)$

Incidence of motor block according to

- The patient (\%)

$0(0 / 492)$

- The patient's chart (\%)

$9.5(33 / 344)$

PONV: postoperative nausea and vomiting

All side effects incidence are cumulative over the entire period from surgery until the visit of the auditor 


\section{Patient's questionnaire $\mathbf{n}^{\circ}$}

Name of the institution:

FINESS number: Date and time of the visit

This questionnaire is used for a national survey collecting information on postoperative pain in surgical patients. It will provide information about the quality of pain management. The person helping you to complete this questionnaire does not belong to the surgical department in which you are being treated. All your answers will remain anonymous. Thank you for taking the time to complete this questionnaire

1. Do you remember receiving any information about pain?

Yes $\square \quad$ No $\square$ Do not remember $\square$

If yes: Oral $\square$ Written $\square \quad$ Satisfied $\square \quad$ Not satisfied $\square$

2. Did you receive a written contract concerning pain management?
Yes $\square$
No
Do not remember

3. Did doctors or nurses encourage you to tell them about unrelieved pain before surgery and during your stay in hospital?

Yes $\square$

No $\square$

4. Was the surgical site painful before surgery? Yes $\square \quad$ No $\square$

If your answer is "no", go directly to question 6

If yes, for how long did the pain last ?

$<1$ day $\square \quad<1$ week $\square<1$ month $\square<1$ year $\square>1$ year $\square$

This pain was: continuous $\square$

intermittent $\square$

This pain was present at rest:

Yes $\square$ Noo $\square$

This pain was present on movement:

Yes $\square$ No $\square$

5 . Which number best describes the pain before surgery (at least 24 hours before)?

Choose a number from 0 to 10 ( $0=$ no pain; $10=$ unbearable pain $)$

At rest

On movement

6. Did you suffer any pain, even if only slight, during the last 24 hours following surgery?

Yes $\square \quad$ No $\square \quad$ Not applicable $\square$

If your answer is "no", go directly to question 9

If not applicable, why?

7. This pain was: continuous $\square \quad$ intermittent $\square$ ?

This pain was present at rest: $\quad$ Yes $\square$ No $\square$

This pain was present on movement: $\quad$ Yes $\square$ No $\square$

8. Which number best describes your pain now?

Choose a number from 0 to 10 ( $0=$ no pain; $10=$ unbearable pain $)$

At rest

On movement

9. What number best describes your maximum pain since surgery?

Choose a number from 0 to 10 ( $0=$ no pain; $10=$ unbearable pain $)$ 
Did the patient receive any analgesic? $\quad \square$ Yes $\quad \square$ No

10. [If yes] which number best describes the relief obtained by the analgesic prescribed now?

Choose a number from 0 to 10 ( $0=$ no relief; $10=$ total relief $)$

11. Did you ask for rescue analgesia? $\square$ Yes $\square$ No

12. If yes, why?

$\square$ You were in pain at the time

This time was $\square$ at the first occurrence of pain $\square$ when pain was too intense

$\square$ You were anticipating pain

$\square$ You did not want to bother the nurse later

$\square$ You did not want to be bothered later

$\square$ Other

13. If you received rescue analgesia, what maximum time elapse between your request and the administration of the analgesic?

$\square$ Less than 5 minutes

$\square 15$ minutes or less

$\square 15$ to 30 minutes

$\square 30$ to 60 minutes

$\square$ More than an hour

No treatment was administered. Why?

14. Did the treatment you received to relieve your pain induce side effects?

Yes $\square$ No $\square$

15. If yes, which side effects were induced?

Nausea/vomiting $\square$ Sleepiness $\square$ Constipation

Pruritus $\square$ Difficulty urinating $\square \quad$ Other

16. Which number best describes the intensity of these side effects?

Choose a number from 0 to 10 ( $0=$ none; 10 = unbearable):

17. Which number best describes your usual level of anxiety?

Choose a number from 0 to $10(0=$ no anxiety; $10=$ unbearable anxiety $)$

18. Which number best describes your past or present anxiety concerning your surgery?

Choose a number from 0 to $10(0=$ no anxiety; $10=$ unbearable anxiety $)$

19. Which number best describes your satisfaction with the role of doctors and nurses in pain management?

Choose a number from 0 to $10(0=$ not satisfied at all; $10=$ totally satisfied $)$

20. Which number best describes your overall satisfaction with pain management?

Choose a number from 0 to $10(0=$ not satisfied at all; $10=$ totally satisfied $)$

21 . If you are not totally satisfied with your pain management, can you explain why?

What improvements would you suggest? 
Auditor's comment

Thank you for your cooperation 


\section{Questionnaire relating to the patient's chart's $\mathbf{n}^{\circ}$}

Name of the institution:

FINESS number:

\section{General information}

Patient: Age: years $\operatorname{man} \square$ woman $\square$;

Date and time of the visit ; of surgery

Location of the patient at the time of the auditor's visit:

Recovery room (RR) $\square \quad$ Surgery $\square \quad$ Intensive care $\square \quad$ Other $\square$

\section{Evaluation of surgery and anesthesia:}

Elective surgery $\quad$ Yes $\square \quad$ No $\square$

Orthopedic $\square$ Visceral surgery $\square$ Urology $\square$ Gynecology / obstetrics $\square$ Pediatric $\square$ ENT stomatology $\square$ Cardiac-vascular $\square$ Thoracic $\square$ Neurosurgery $\square$ Other

Type of surgery in detail

Duration of surgery: $<1$ hour $\square \quad 1-2$ hours $\square \quad>2$ hours $\square$

Anesthesia : General $\square \quad$ Epidural $\square \quad$ Spinal $\square \quad$ Peripheral block $\square$ Local $\square$ Sedation $\square \quad$ Other

\section{Preoperative information about pain}

Information of the patient about pain is mentioned on the chart? Yes $\square$ No $\square$

A postoperative analgesic protocol is planned and mentioned on the chart?

Yes $\square$ No $\square$

A contract concerning pain management is mentioned in the chart? Yes $\square$ No

\section{Evaluation of postoperative pain}

Postoperative pain evaluation prescribed? Yes $\square$ No $\square$

If evaluation was not prescribed, is there any evaluation protocol? Yes $\square$ No $\square$

Is any written pain score since surgery available from the chart (previous $24 \mathrm{hrs}$ ):

- In the RR? Yes $\square$ No $\square$ Not applicable $\square$ If not applicable, why?

- In the surgical ward (at least one value since surgery)?

Yes $\square$ No $\square$ Patient in the RR or ICU $\square$

If yes, which support for the written transmission?

Nurse's report $\square$ Specific document $\square$

Which frequency of written pain's evaluation?

According to the chart: Daily $\square$ Multiple evaluation $\square$ interval h

According to nurses: Daily $\square$ Multiple evaluation $\square$ interval $\mathrm{h}$

Was pain evaluation a criterion for the patient's discharge from the recovery room?

Yes and applied to the patient $\square \quad$ Yes but not applied $\square$ No $\square$

If a written evaluation was available in the recovery room:

- Last written pain score in the recovery room (NS)

Type of scale: If other, please specify: 
- Pain evaluation performed after administration of an analgesic?

$\begin{array}{ll}\text { According to the chart } & \text { Yes } \square \text { No } \square \\ \text { According to nurses } & \text { Yes } \square \text { No } \square\end{array}$

-Was pain evaluated at rest $\square$ on movement $\square$ ? (if doubt, consider at rest)

-Autoevaluation scale: VAS $\square$

Numerical scale $\square \quad$ Verbal scale $\square$

Non specific measure $\square \quad$ Other:

- Maximum pain score values available on the chart:

\begin{tabular}{|l|l|l|l|l|}
\hline \multirow{2}{*}{} & \multicolumn{2}{|c|}{ AT REST } & \multicolumn{2}{c|}{ ON MOVEMENT } \\
\cline { 2 - 5 } & Score & Scale & Score & Scale \\
\hline Recovery room & & & & \\
\hline $\begin{array}{l}\text { First night after } \\
\text { surgery }\end{array}$ & & & \\
\hline $\begin{array}{l}\text { On D1, at the time } \\
\text { of the auditor's visit }\end{array}$ & & & & \\
\hline
\end{tabular}

\section{Evaluation of side effects of analgesia}

Prescription mentioning the monitoring of the side effects of analgesia Yes $\square$ No $\square$

Prescription mentioning guidelines for treatment of the side effects Yes $\square$ No

If no prescription of guidelines, protocols to treat side effects are available Yes $\square$ No $\square$ Analgesia's side effects are evaluated?

$\begin{array}{ll}\text { According to the chart } & \text { Yes } \square \text { No } \square \\ \text { According to nurses } & \text { Yes } \square \text { No } \square\end{array}$

If yes, which document was used for the written evaluation of the side effects?

Nursing report $\square$ Specific document $\square$

Were specific scores are used to evaluate the side effects? $\quad$ Yes $\square$ No $\square$

Any side effects written in the chart:

Nausea / vomiting Yes $\square$ No $\square \quad$ Sedation Yes $\square$ No $\square$
Motor block Yes $\square$ No $\square \quad$ Pruritus Yes $\square$ No $\square$ Urinary retention Yes $\square$ No

\section{Prescription of analgesics}

- Intraoperative analgesia : Yes $\square$ No $\square$

Ketamine $\square$ Clonidine $\square$ Paracetamol $\square$ Ketoprofen $\square$ Nefopam $\square$ Tramadol $\square$ Morphine $\square$ Other $\square$

Intrathecal analgesia: Yes $\square \mathrm{No} \square$

morphine $($ dose $\mu \mathrm{g}) \ldots$ _

- Analgesics prescribed before a provoked pain (according to the chart): Yes $\square$ No $\square$ If yes, under what conditions: $\quad$ physiotherapy $\square \quad$ nursing $\square$ mobilization $\square$

- Opioid treatment Yes $\square \quad$ No $\square$ 
Prescription of morphine titration Yes $\square$ No $\square$

If yes: No bolus $\square \quad$ Bolus $\square \_$mg Interval __ min

-Oral morphine $\quad$ Yes $\square \quad$ No $\square$

-Patient-controlled morphine $\quad$ Yes $\square \quad$ No $\square$

If yes: analgesic used: Morphine $\square$ Other $\square$ Which?

Bolus dose (mg) Interval $\min$

-Subcutaneous morphine Yes $\square \quad$ No $\square$

Administration: fixed schedule (FS) $\square \quad$ PRN $\square \quad$ not defined $\square$

Criterion for PRN administration?

Interval between doses: / $4 \mathrm{~h} \square / 6 \mathrm{~h} \square / 8 \mathrm{~h} \square / 12 \mathrm{~h} \square$ not defined $\square$

Dose: $5 \mathrm{mg} \square 10 \mathrm{mg} \square$ other $\square$ Respected: Yes $\square$ No $\square$ Not applicable $\square$

\begin{tabular}{|c|c|c|c|c|c|}
\hline Opioid & $\begin{array}{l}\text { Administration } \\
\text { (IV/PO) }\end{array}$ & Dose (mg) & $\begin{array}{l}\text { Interval } \\
\text { (h) }\end{array}$ & FS / PRN & Respected \\
\hline Tramadol & & & & & Yes $\square \mathrm{No} \square \mathrm{NA} \square$ \\
\hline Buprenorphine & & & & & Yes $\square \mathrm{No} \square \mathrm{NA} \square$ \\
\hline Nalbuphine & & & & & Yes $\square \mathrm{No} \square \mathrm{NA} \square$ \\
\hline $\begin{array}{ll}\text { Codeine } & +/- \\
\text { paracetamol }\end{array}$ & & & & & Yes $\square$ No $\square$ NA $\square$ \\
\hline $\begin{array}{ll}\text { Dextro } & +/- \\
\text { paracetamol }\end{array}$ & & & & & Yes $\square$ No $\square$ NA $\square$ \\
\hline
\end{tabular}

\begin{tabular}{|c|c|c|c|c|}
\hline Other opioid & Dose (mg) & Interval (h) & FS / PRN & Respected \\
\hline & & & & Yes $\square$ No $\square$ NA $\square$ \\
\hline & & & & Yes $\square$ No $\square$ NA $\square$ \\
\hline & & & & Yes $\square$ No $\square$ NA $\square$ \\
\hline
\end{tabular}

- Non opioid analgesics? Yes $\square$ No $\square$

\begin{tabular}{|c|c|c|c|c|}
\hline Analgesic & $\begin{array}{l}\text { Dose } \\
\text { (mg) }\end{array}$ & $\begin{array}{l}\text { Interval } \\
\text { (h) }\end{array}$ & FS / PRN & Respected \\
\hline Paracetamol & & & & Yes $\square$ No $\square$ NA $\square$ \\
\hline NSAID: type of NSAID & & & & Yes $\square \mathrm{No} \square \mathrm{NA} \square$ \\
\hline Parecoxib & & & & Yes $\square$ No $\square$ NA $\square$ \\
\hline Nefopam & & & & Yes $\square$ No $\square$ NA $\square$ \\
\hline \multicolumn{5}{|c|}{$\begin{array}{l}\text { Other analgesic (e.g. } \\
\text { celecoxib...) }\end{array}$} \\
\hline & & & & Yes $\square \mathrm{No} \square \mathrm{NA} \square$ \\
\hline & & & & Yes $\square$ No $\square$ NA $\square$ \\
\hline
\end{tabular}


Lumbar epidural $\square$ Thoracic epidural $\square$

Analgesic: Bupivacaine $\square$ Ropivacaine $\square$ Lidocaine $\square$ Morphine $\square$ Sufentanil $\square$ Type of administration: Bolus $\square \quad$ Continuous infusion $\square \quad$ Patient-controlled $\square$

- $\quad$ Continuous peripheral nerve block Yes $\square \quad$ No $\square$ Interscalene $\square \quad$ Axillary $\square \quad$ Lombar posterior $\square$ Femoral $\square \quad$ Sciatic $\square$ Local anesthetic: Bupivacaine $\square \quad$ Ropivacaine $\square \quad$ Lidocaine $\square$ Type of administration: Bolus $\square$ Continuous infusion $\square$ Patient-controlled $\square$

Are there any protocols for the treatment of postoperative analgesia? Yes $\square$ No $\square$ Has the analgesic treatment been adapted since surgery? Yes $\square \quad$ No $\square$ If yes, how? 


\section{Questionnaire for the local postoperative pain specialist}

Characteristics of the institution (several answers possible)

Regional public hospital $\square$ Local public hospital $\square \quad$ Public teaching hospital $\square$

PSPH (private hospital belonging to the public hospital network) $\square$

Cancer institute $\square \quad$ Private hospital

Total number of beds

Number of surgical beds

Operative site___ Operating rooms Anesthesiologists (full time) Anesthesia

Nurses (full time)

Number of surgical act per year

Type of surgery

Orthopedic $\square$ Visceral surgery $\square$ Urology $\square$ Gynecologic-obstetrics $\square$ Pediatric $\square$ ENT stomatology $\square$ Cardiac-vascular $\square$ Thoracic $\square$ Neurosurgery $\square$ Day surgery $\square$ Over the period 2001, 2002, 2003, surgical activity (excluding same day surgery)was ? Increasing $\square \quad$ Diminishing

Number of surgical stay $(>24 \mathrm{~h}$ )

-2001 :

-2002 :

-2003 :

\section{Patient's information}

Is systematic information of the patient concerning pain planned?

Yes $\square \quad$ No $\square$

Is yes, in what form is this information given? (several answers possible)

Written information in a specific document $\square$

Oral information at the time of preoperative visit

\section{Pain evaluation}

Is pain evaluated after surgery?

Yes $\square \quad$ No $\square$ If yes, where? $\quad$ Recovery room $\square \quad$ Surgery $\square$

Is pain score a criterion for recovery room discharge $\quad$ Yes $\square \quad$ No $\square$

Do you have protocols for postoperative pain evaluation? Yes $\square$ No $\square$

How often is pain evaluated?

Daily $\square \quad$ Several time per day $\square$ which interval (h) ? Do not know $\square$

How is pain evaluated?

Evaluation scale: VAS $\square \quad$ Numerical scale $\square \quad$ Verbal scale $\square$

Non specific scale $\square$ Other

At rest $\square$ On movement $\square$

Do you have protocols for evaluation and treatment of side effects? Yes

No $\square$

\section{Treatment}

Who prescribes analgesics? : Anesthesiologists $\square$ Surgeons

Both $\square$ 
Agreement anesthesiologist/surgeon for pain treatment: Yes $\square$ No $\square$ Oral $\square$ Written How do you contact the doctor who prescribes during the day? Pager $\square$ Secretary $\square$ other $\square$ How do you contact the doctor who prescribes at night? Pager $\square$ Secretary $\square$ other $\square$ Do you have protocols for treating postoperative pain? $\quad$ Yes $\square$ No $\square$ Do you have technical guidelines concerning postoperative pain? Yes $\square$ No $\square$ These documents are available:

- In the recovery room? Yes $\square$ No

- In all surgical department? Yes No $\square$

- In intensive care unit? Yes Not applicable

- Elsewhere? Yes No $\square$ If yes, please specify

Do you use routinely use morphine titration in the recovery room? Yes $\square$ No $\square$ Do you routinely use patient-controlled analgesia (PCA) Yes No How many PCA pumps (equipment) How many patients treated/week or/ year

Where are patients treated by PCA?

Surgery $\square \quad$ Recovery room $\square \quad$ intensive care unit

Do you routinely use the continuous peripheral nerve block?

Yes $\square \quad$ No $\square$ How many patients / week or / year

If yes, which continuous peripheral nerve block do you routinely use? Interscalene $\square$ Axillary $\square$ Lumbar posterior $\square$ Femoral $\square$ Sciatic $\square$ Do you routinely use epidural analgesia after surgery?

Yes $\square$ No $\square$ How many patients / week / year

Where are patients treated treated by epidural?

Surgery $\square$ Recovery room $\square$ intensive care unit $\square$

Do you use intrathecal analgesia?_Yes $\square \quad$ No $\square$

Intrathecal morphine Yes $\square$ No $\square$ unitary dose (mg) for young ASA 1 patient

\section{Organisation, evaluation, quality}

Pain management is one element of the department project Yes $\square \quad$ No $\square$ Is there a postoperative pain quality program? Yes $\square \quad$ No $\square$ Is an anesthesiologist contactable round the clock? Yes $\square \quad$ No $\square$

Do you have paramedical or medical staff specifically responsible for pain management?

Yes $\square \quad$ No $\square$ if yes, how many? do not know $\square$

Do you have an acute pain team in your establishment? Yes $\square$ No $\square$ Is nurse training regularly updated: Yes $\square$ No $\square$ Do not know $\square$

Do you have a local pain management committee? Yes $\square \quad$ No $\square$ Do not know $\square$ Education (Diplomas, congresses, local training, meetings).

Do the doctors have training in pain management?

Yes $\square \quad$ No $\square$ if yes, how many? Nature of training

Do the nurses have training in pain management? 
Yes $\square \quad$ No $\square$ if yes, how many? Nature of training

How many training sessions relating to pain were held in your establishment in 2003 ? (education department) Doctors Nurses

\section{Pharmacy}

Opioid use in the recovery room and in surgery in 2001, 2002, 2003 was? Increasing $\square \quad$ Diminishing $\square \quad$ Stable $\square$

Peripheral nerve catheter use in the recovery room and in surgery in 2001, 2002, 2003 was? Increasing $\square \quad$ Diminishing $\square \quad$ Stable $\square$

The use of special connecting equipment for PCA in 2001, 2002, 2003 was? Increasing $\square \quad$ Diminishing $\square \quad$ Stable $\square$

Free comments from the pain control doctor or nurse: 